\title{
Effect of mechanical vibration on the residual stress of direct laser metal
}

\section{deposition workpiece}

\author{
Yi-Qun Feng ${ }^{1}$, Hsuan-Han Lai ${ }^{1}$, Chi-Ming Lin $^{1}$ and Weite $\mathrm{Wu}^{1,{ }^{*}}$ \\ ${ }^{1}$ National Chung Hsing University, Department of Materials Science and Engineering, 250 Kuo \\ Kuang Road, Taichung 402, Taiwan, R.O.C
}

Keywords: Direct laser metal deposition, mechanical vibration, residual stress.

\begin{abstract}
Mechanical vibration with different frequencies was operated during the direct laser metal deposition process in order to discuss the effects of vibration on residual stress and other characters of deposited workpiece in this study. Sub-resonance, resonance and the optimum frequency (OPF) were selected for operation. The results revealed that the residual stress of the deposited workpiece was a tensile stress. With the operation of mechanical vibration, the stress of clad workpiece decreased, and the workpiece vibrated with the OPF showed the lowest residual stress. Microstructures of all the specimens with vibration refined, and the finest structure appeared in the specimen vibrated with the OPF. The hardness result showed that the lower the residual stress was, the lower the hardness was, and a low residual stress and hardness would have advantage of subsequent process of the deposited workpiece.
\end{abstract}

\section{Introduction}

Additive manufacturing, or 3D printing, is one of the most popular technologies nowadays. It is more flexibility than traditional manufacturing and it can create a more complex shape of the workpiece. Direct laser metal deposition is one of those techniques, which has the advantages of building large volume workpiece and refurbish worn or damaged components [1].

The basic principle of direct laser metal deposition is melting and solidification of the metal powder and it is similar to welding process. Therefore, as the welded workpiece, the deposited clad shows residual stress. A high residual stress leads to distortion or cracks during the subsequent process of workpiece. It has been reported that the operation of mechanical vibration during welding process will bring about a lower residual stress of the workpiece [2]. In order to reduce the residual stress of the direct laser metal deposited workpiece, in this study, the mechanical vibration with different frequency was applied to the deposition process, and the residual stress, microstructure and hardness of the clad were examined and discussed.

\section{Experiments}

Fig. 1 illustrated the deposition process. The deposition process was carried out using a robotic arm which carried a coaxial laser cladding nozzle. The base metal was a low carbon steel SS400 with dimensions of $200 \mathrm{~mm} \times 100 \mathrm{~mm} \times 20 \mathrm{~mm}$. The powders used for deposition were commercial SKD 61 and Inconel 718, and the particle size was ranged between 45-105 $\mu \mathrm{m}$. Detailed deposition parameters were: laser power $2 \mathrm{~kW}$, nozzle moving speed $10 \mathrm{~mm} / \mathrm{s}$, powder feeding rate $40 \mathrm{~g} / \mathrm{min}$, powder carrier gas (also the shielding gas) flow rate $2-4 \mathrm{~L} / \mathrm{min}$, and 4 clad layers. The selected vibration frequencies were the resonant frequency, sub-resonant frequency and the optimum frequency (OPF). The vibrator operated in the whole laser deposition process. The 
analyzed area was also illustrated in Fig. 1, which was the middle part of the top surface of the clad. The area was ranged about $10 \mathrm{~mm}$.

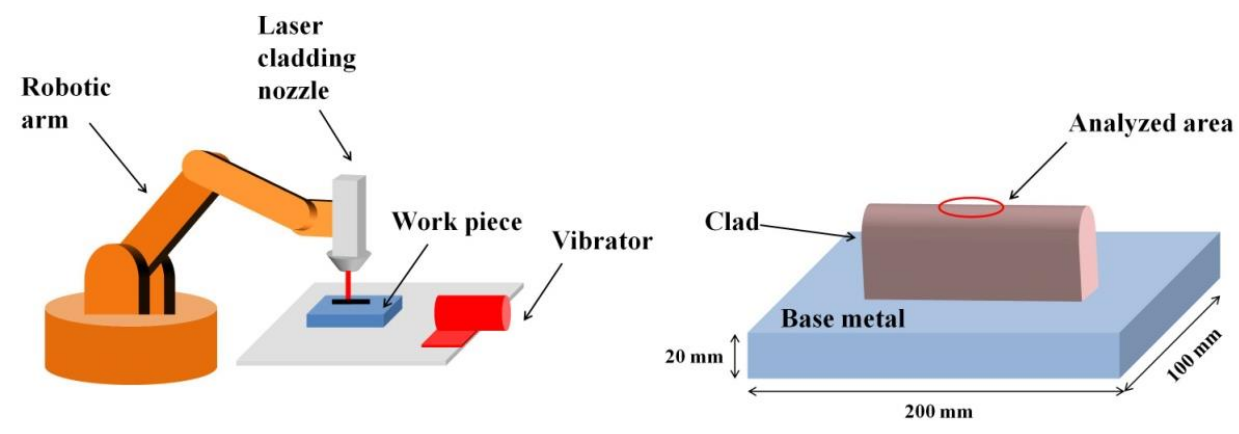

Fig. 1 Illustrations of the deposition process and the analyzed area.

The residual stress of the clad specimen was measured before any other analysis. The specimens were not grinded. A X-ray residual stress analyzer (Pulstec Industrial Co., Ltd., $\mu-X 360$ ) was selected to measure the stress of specimens, with a $\mathrm{Cr}$ target, the accelerating voltage $20 \mathrm{kV}$, emission current $1 \mathrm{~mA}$. The microstructures of the clad were observed using an optical microscope Specimens were grinded and polished. The etchant was $50 \% \mathrm{HNO}_{3}$ solution for SKD 61 specimen and $25 \% \mathrm{HCl}, 75 \% \mathrm{HNO}_{3}$ for Inconel 718 specimen. The surface hardness was determined using a Vickers hardness tester with a $0.49 \mathrm{~N}(0.05 \mathrm{~kg})$ load.

\section{Results and discussion}

Fig. 2 illustrated the residual stress of laser deposited specimens with different vibration frequencies. All the specimens had tensile stresses. During the deposition process, the metal powders were melted by laser and were blown to the base metal by the carrier gas. The clad formed when the melted powder solidified onto the base metal, and it would also shrinkage, resulting in the formation of a tensile stress in the clad [3]. A high residual tensile stress might lead to the cleavage of the deposited clad. When mechanical vibration was carried out during deposition, the residual stress of all the specimens was reduced. For the SKD 61 specimens, the stress was over $200 \mathrm{MPa}$ when the vibrator did not operate during the deposition process; with the addition of mechanical vibration, the stress of the specimen could be lower than $130 \mathrm{MPa}$. For the Inconel 718 specimen, although the stress reduction was not as much as that of SKD 61, the stress could still be lowered from $268 \mathrm{MPa}$ (without vibration) to $133 \mathrm{MPa}$. From Fig. 2 it was also concluded that the deposition process with the OPF vibration could show the lowest residual stress of the clad. For both the SKD 61 and Inconel 718 specimen with the OPF vibration, the stresses were over 50\% lower than those deposited without vibration.

Fig. 3 presented the microstructure of deposited SKD 61 clad, and Fig. 4 was that of Inconel 718 clad. For SKD 61 clad, as in Fig. 3, dendritic morphology was the main solidification structure. When the sub-resonant frequency was applied to the deposition process, the dendrite size decreased slightly. For the specimen with resonant frequency, the morphology did not change obviously. As the vibration frequency came to the OPF, the dendrite size decreased obviously. For the Inconel 718 clad, as in Fig. 4, the solidified structure was also dendritic structure. For the clad with the OPF vibration, the long dendrite did not appear. With the operation of mechanical vibration, the melted metal is stirred during solidification. It causes the reducing in the nucleant size and also the changing of growth direction [4][5]. During the deposition process, the powders were melted by laser and solidified on the attached location. This was like a welding process. Therefore, with the 
addition of mechanical vibration, the solidified morphology showed large difference comparing with that without vibration. For both the SKD 61 and Inconel 718 clad, deposition with the OPF vibration could obtain the finest solidified structure.

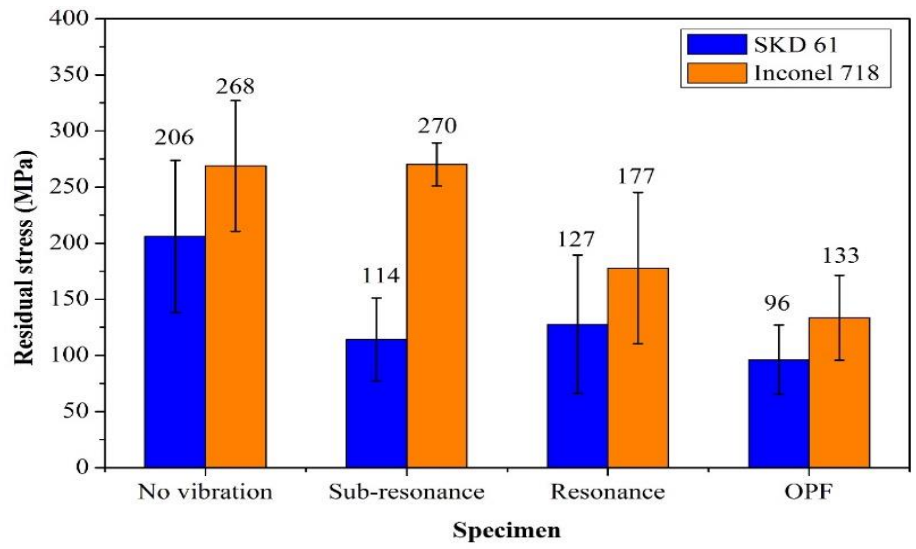

Fig. 2 Residual stress of clad specimens with different vibration frequencies.

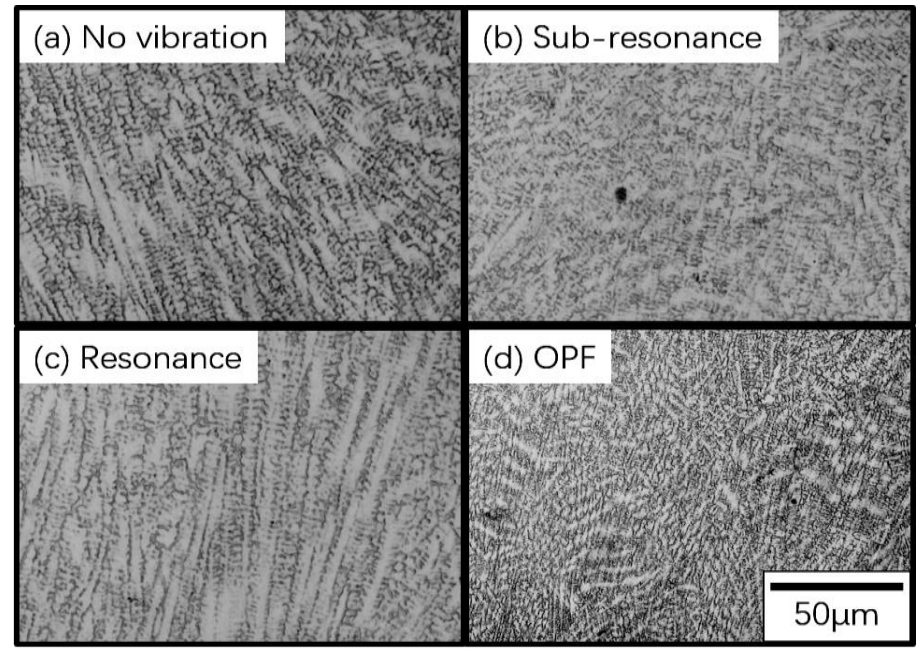

Fig. 3 Microstructures of SKD 61 clad.

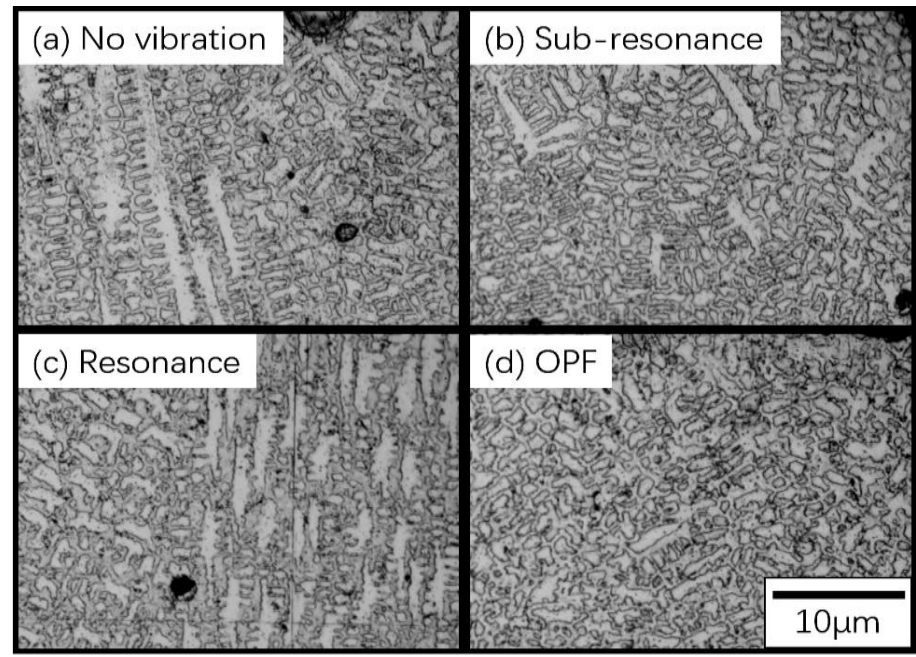

Fig. 4 Microstructures of Inconel 718 clad.

Fig. 5 presented the hardness of SKD 61 and Inconel 718 clad with different vibration 
frequencies. The hardness of clad without vibration was $83 \mathrm{HV}$ for SKD 61 and $334 \mathrm{HV}$ for Inconel 718. As mechanical vibration was operated during deposition, the hardness of all the clad specimen decreased. The hardness of SKD 61 could be as low as $721 \mathrm{HV}$ and that of Inconel 718 was $296 \mathrm{HV}$. Comparing Fig. 2, 3, 4 and 5, for both SKD 61 and Inconel 718 clad, the specimen vibrated with the OPF showed the lowest residual stress and also a lower hardness. It could also be concluded that the lower the residual stress was, the lower the hardness. Since the direct laser metal deposition work piece usually needs further processing, the decrease in residual stress and hardness would make it easier to manufacture.

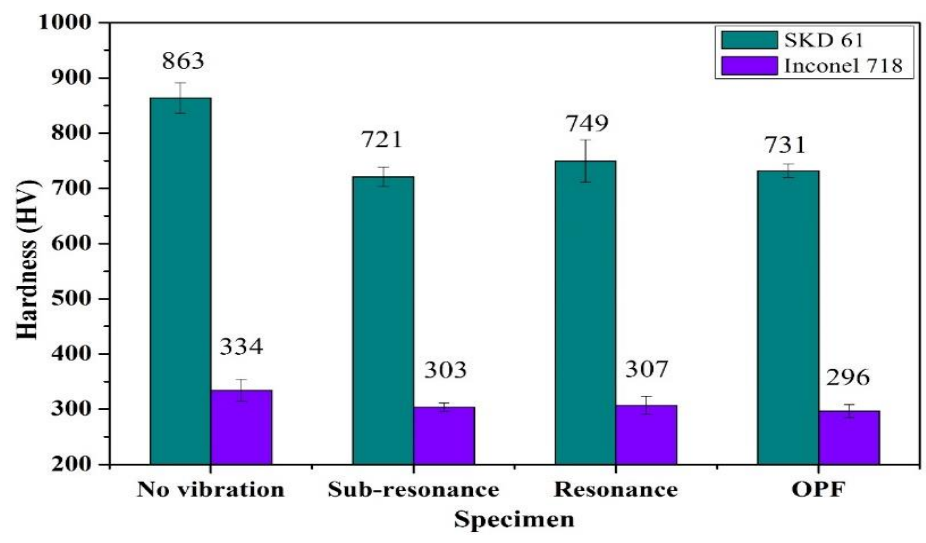

Fig. 5 Hardness of clad specimens

\section{Conclusions}

In this study, different mechanical vibration frequencies were applied to the direct laser metal deposition process and the residual stress, microstructure and hardness of the clad specimen were measured and discussed. The conclusions of this study are listed below:

1) The deposited clad presented a tensile residual stress.

2) With the operation of mechanical vibration, the residual stress of both SKD 61 and Inconel 718 clad specimen could be lowered, and the specimen with the OPF showed the lowest residual stress.

3) The microstructure of clad specimen could be refined with the operation of mechanical vibration. The specimen vibrated using OPF had the finest structure.

4) The hardness of clad specimen was lowered when mechanical vibration was applied to the deposition process.

\section{Acknowledgment}

The authors would like to acknowledge the financial support of the Ministry of Science and Technology under projects MOST 105-2221-E-005-018、MOST 105-2218-E-005-014、MOST 105-2622-8-006-001 and MOST 105-2218-E-005-005.

\section{References}

[1] W. E. Frazier, Journal of Materials Engineering and Performance, 23 (2014) 1917 - 1928.

[2] J. Xu, L. Chen, C. Ni, International Journal of Pressure Vessels and Piping, 84 (2007) 298 303.

[3] S. Kou, Welding metallurgy, $2^{\text {nd }}$ ED., A John Wiley \& Sons, New Jersey, pp.122-124 (2003).

[4] K. Kocatepe, Materials and Design, 28 (2007) 1767 - 1775.

[5] C.W. Kuo, S.M. Yang, J.H. Chen, G.H. Lai, Y.C. Chen, Y.T. Chang, W. Wu, Materials Transactions, 49 (2008) 688 - 690. 